\title{
A Philosopher's View of Near-Death Research
}

\author{
Carl B. Becker, Ph.D., D.Litt. \\ Kyoto University, Japan
}

\begin{abstract}
This article summarizes some trends and issues raised by a review of recent articles in the Journal of Near-Death Studies. It points to a need for clarity on the problems of monism and dualism, on the definitions of near-death experiences (NDEs), on reasoning by analogy, and on hypothesis testing and falsification. While recognizing the superficial similarities between NDEs and a broad range of spiritual experiences, psychotic syndromes, and psychological states, it urges a nonreductionistic focus on those issues amenable to recognized research methodologies.
\end{abstract}

The International Association for Near-Death Studies (IANDS) is approaching its 15th year, and it has grown from a liberal bunch of long-haired or bearded interns and graduate students of the '70s into a mainstream organization attracting renowned scholars to speak at its conferences and write for its professional quarterly Journal of Near-Death Studies. I am extremely gratified by this progress, and depend heavily on the Journal both to keep abreast of the latest thinking in the field, and to publicize the legitimate scholarly nature of near-death research to colleagues and other professionals. Lest any of the following comments be misconstrued, let me first say that I am deeply grateful to the many authors, reviewers, and editors of the Journal for the efforts and energies they pour into this research and its publication.

Kyoto University is known for being Japan's leading university in philosophy, and I am privileged to teach some very gifted graduate

Carl B. Becker, Ph.D., D.Litt., is Associate Professor of Human Sciences at Kyoto University. Reprints should be addressed to Dr. Becker at the Department of Human Sciences, Kyoto University, Nihon-Matsu-cho, Yoshida, Sakyo-ku, Kyoto, Japan 60601. 
students there. Recently, we studied the last few years of the Journal, to compare the latest English-language near-death research with that conducted by Tachibana Takashi in the magazine Bungei Shunju. This article summarizes some trends and problems our study revealed. This study may enable future writers to avoid certain conceptual and linguistic confusions, and may possibly have policy implications for review standards that our Journal will want to maintain.

\section{Monism and Dualism}

From the pre-Socratics to the latest in philosophical encyclopedias, monism has meant the doctrine that everything is ultimately reducible to one underlying substrate. Materialist monists, such as Karl Marx and Mao Tse Tung, reduced everything to matter. Idealist monists, such as George Berkeley and Mary Baker Eddy, reduced everything to ideation. By contrast, dualism holds that two fundamentally disparate kinds of essence make up the universe: physically extended matter, and nonphysical mentation. While monists face philosophical problems in explaining phenomena that do not seem to fit their reductionist modes, dualists also face philosophical problems in explaining the connection and interaction of two fundamentally unrelated kinds of stuff.

This is not the time nor the place to take sides on this millenniaold debate. It is important to note that all of the above theories are inherently problematic, some more than others; that none of the above theories is unequivocally supported or denied by what we know of near-death research to date; that while personal survival of death would stretch the bounds of materialist monism as we know it, still, if the surviving personality were embodied and extended, there need be no fundamental conflict with a monist materialism, extended to allow for other dimensions. The assumptions that monism is necessarily materialism, that materialism is necessarily reductionist monism, and that either is incompatible with near-death experience (NDE) data, are far from demonstrated, although some writers, such as Kenneth Arnette (1992), seem to write from such assumptions.

At the same time, the fact that people see different things in their NDEs no more proves that NDEs are illusory or self-created than the fact that people sailing around the world see different things in their different cruises proves that their journeys are all hallucinations. While the law of parsimony immortalized as Ockham's razor 
is indeed to be applied to scientific theories, as John Wren-Lewis (1992) wrote, it simply advises us that "entities are not to be multiplied without necessity; that nothing is to be assumed as necessary, in accounting for any fact, unless it is established by evident experience or evident reasoning, or is required by the articles of faith." So William of Ockham would be the last scholar to reduce NDEs to physicalist or materialist monism, because there are facts of "evident experience" that cannot be accounted for without resorting to entities or aspects not yet understood by physical science (Becker, 1993).

\section{Internal and External Experiences}

We must distinguish clearly between experiences as observed from the outside and as personally experienced. This is one difference between Western medicine, based on examining cadavers and brain functions from the outside, and Eastern medicine, based on knowing one's own psychophysiological responses to drugs, acupuncture, and meditation. Each has its place; neither is complete in and of itself. Since the NDE is above all an experience, it is amenable to both kinds of observation. Any overemphasis on either side would be a distortion.

Let me illustrate this concern with the example of falling in love; feeling at peace, making a discovery, bidding farewell, or any of a number of other examples might do. Let us imagine that at some future point, neuroscience will become so advanced that it can "explain" falling in love physicochemically. It can identify which chemicals the body releases at which moment and are picked up by which sense receptors; which ions must cross which neuronal membranes to produce the required loss of concentration or appetite; which infantile imprints or fantasies are subconsciously superimposed on the other person, and so on. Indeed, if such an analysis were possible, it might then also be possible to influence people to fall in or out of love, which would have important ethical and behavioral ramifications.

Would anyone be so obtuse as to say that that physicochemical explanation is what love feels like and means to the parties who gaze into each others' eyes? Surely the feeling of love and the meaning of love are extremely significant regardless of whether its biophysical mechanisms are known. For a scientist who had never experienced the emotion to say he now "understood" love because he could explain 
it neurologically would be as misguided as those critics of transcendental experiences who try to "explain" them by physicochemical explanations but have never experienced ecstasy, or those who would dismiss out-of-body experiences (OBEs) as mental disturbances, although they themselves have never been out of body.

There is much need for neurophysiological research. It may contribute substantially to our understanding of brain functions, even of when, how, and why people have what kind of NDEs. But let us not mistake the correlating of NDEs to neurophysical events with the idea that they can somehow be reduced to neurophysical processes. Surely the most important aspects of the NDE, the OBE, religious ecstasy, falling in love, and other subjective phenomena are present in the experience and impact in the life of the experiencer, regardless of whether their neurophysiological correlates can be identified. At the same time, this does not mean that each experiencer is an expert on the subject; on the contrary, one's own experience may color one's perceptions to the extent that one is unable to admit other experiences or interpretations, and we see this trend among many of the near-death experiencers whose papers appear in this Journal.

\section{Definitions of Near-Death Experiences}

The problem is confounded by the lack of clarity about what we mean by NDEs. Originally, we used the term NDE to refer to experiences of those near to death. But how near to death does one need to be? a week away in a hospital? psychologically prepared to die, like Golden Gate Bridge suicide attemptors? spiritually ready to be absent from the body, like some meditators? or physically in the throes of death? As recent studies take an ever broader view of what constitutes NDEs, it becomes ever harder to tell what can be excluded as not being an NDE.

Classic approaches to this problem use the ideas of "core experiences," a Weighted Core Experience Index (WCEI) (Ring, 1980), or family resemblances between experiences. Philosophically speaking, the WCEI type of approach is problematic if it fails to distinguish essential and nonessential characteristics.

Consider as an analogy the definition of a university. There are surely a great number and variety of universities. Some have gymnasiums and swimming facilities; others do not. Some have their own 
bookstores, some their own cafeterias, some their own hospitals or hotels or lakes or desert islands. All of these are what we might call "incidental" features of universities; it is possible to be a university without having your own lake or desert island. On the other hand, there are certain features that are essential to universities, without which we would be hard pressed to call something a university. For example, if the institution had no faculty, or no administration, no post-secondary students, no research programs or facilities, or no degree-granting powers, then we could rightfully say that the institution were not a proper university, the way the term is understood in English.

A similar argument can be made about NDEs. Features like tunnels, noises, out-of-body experiences, and life-reviews, while somewhat common, are hardly unique to NDEs. They are all producible by physicochemical means, can be encountered in meditation, and are philosophically peripheral or incidental to the core experience. There is no question that physical stimulation can produce these parts of the NDE, as researchers like Susan Blackmore and Tom Troscianko (1989) have taken great pains to emphasize. The question becomes rather, are there parts of the NDE that cannot be so mechanically produced?

Deathbed visions of departed friends, religious figures, or of a "next world" are fundamental to the NDE, having direct reference to death and the hereafter, and directly affecting the individual's feeling about death and the afterlife. It would make good philosophical sense to distinguish between NDEs that refer to death or the hereafter, and those incidental to that core experience. I have argued this point in great detail elsewhere (Becker, 1993).

\section{Association Games, or Reasoning by Analogical Implication}

A number of articles over the past few years have involved the association game of "that reminds me of ...." For example, NDEs remind various people of multiple personality disorder and child abuse cases (Serdahely, 1992, 1993); the Garden of Eden, Peggy Sue, and boson condensation (Wile, 1994); wormholes to other dimensions (Arnette, 1992); The Velveteen Rabbit (Kellehear, 1993); Moses in the wilderness (Steinmetz, 1993); kundalini (Kieffer, 1994); and the 
movie "2001," driving the Pennsylvania Turnpike, or a washing machine commercial (my students).

Of all such analogies, we surely must ask: do they shed light on important features of the NDE that are not already known without the use of such analogies? To what extent are they really analogous? Does the author have a hidden (or not so hidden) agenda? Ill-formulated analogies and hypotheses can hurt, at best, the repute of the writer and, at worst, that of the journal that accepts them for publication. Let me elaborate with a few examples.

\section{Multiple Personality Disorder (MPD) and Child Abuse Cases}

William Serdehely suggested that "NDEs and MPD may be variants of the very same experience" $(1992$, p. 37), a "dissociating from a painful body" (1993, p. 93). Several observations need to be made here. First, a great number of NDEs happen to people who have neither been abused as children, nor are in the least need of escaping physical or psychological pain at the time of their near-passing. To generalize that all NDErs are like sexually-abused mental patients because a few of them are commits the same fallacy for which Sigmund Freud became notorious: making pronouncements about the mental health of the populace based on analysis of a few extremely unusual patients.

Second, as a health scientist, Serdahely may be unaware of the analogous debate in anthropological literature concerning the sanity and child abuse of shamans. Since the early part of the 20th century, certain scholars had held that shamans suffered from multiple personality disorder and child abuse, that they had schizophrenic tendencies and were less mentally stable than their peers. However, careful Rorschach testing and other clinical observations have since shown conclusively that shamans not only were not schizoid, but in fact have better mental health than those who lack religious or spiritual grounding (Boyer, Klopfer, Brawer, and Kawai, 1964; Noll, 1985). We could re-run this whole debate through the NDE world if desired. But such a research project is hardly required, because its premises are flawed from the start. The facts that abuse can trigger dissociation and NDEs can trigger dissociation do not mean that all dissociation comes from abuse nor that NDEs all happen to people who have been abused. Most NDErs neither have MPD, have been 
abused, nor are mentally unstable, but have a very healthy outlook on life.

Third, we must look at the implication of this charge. If Serdahely is able to tell his patients with MPD that they are not so abnormal after all, because some people have somewhat similar experiences in NDEs, then this ploy may be clinically useful, regardless of its questionable logic. However, if it leads us to conclude that NDErs are schizophrenic, have MPD, or were abused as children, then this is not only a travesty of logic but borders on slander and libel.

Consider a very sane and sober contributor to this Journal, who had once gone on record as reporting her out-of-body experience (OBE). Imagine she were to apply for a job where someone on the hiring committee had read and believed Serdahely's theory that OBErs are like sexually-abused mental patients. This could easily cost her the job, or create for her severe interpersonal relationship problems after being hired, for reasons at first unclear to her. If she discovers the course of this discrimination, Serdahely will need a good lawyer on retainer.

Hypotheses are all fine and good; but when they threaten the reputations of the very people whom we are trying to encourage to "go public" and discuss their experiences, they are more of a disservice than a service to our fledgling field. So on the grounds of (1) logic, (2) limitations of the data, and (3) the implications for the field, such articles ought to be written, edited, and published with extreme caution.

\section{Wormholes, Boson Condensations, and the Meaning of Life}

The logical mistakes in Kenneth Arnette's (1992) wormhole theory and Lawrence Wile's (1994) explanation of the meaning of life by application of boson condensation theory to Reissner's fiber are analogous, though they vary in elegance. Both wormholes and Reissner's fiber are aspects of the physical world. One (possibly) connects our dimensions with other physical dimensions; the other (possibly) connects the subcommissural organ and the terminal ventricle, serving for buoyancy regulation, as shown forty years ago by the late Masashi Enami (1954) in Japan.

NDEs, however, are not physical movements from our three dimensions to other dimensions. The body of the NDEr or OBEr remains physically in our dimensions. If anything moves physically out 
of the body and through wormholes to other dimensions, it must be some kind of matter of which we have no present knowledge. It does not follow present laws of gravity, friction, inertia, as so on. Proof of its existence would drastically change our understanding not only of wormholes, but of physics altogether. But Arnette presented no evidence of such a new form of matter. He committed the common category mistake of applying a theory to an inappropriate domain, like trying to apply the theory of gravity to trigonometry, or of magnetism to dream interpretation. Even Kenneth Ring sometimes slipped into this trap: holograms (Ring, 1984), like wormholes, are concepts about matter, not about mental experience.

Psychiatrist Wile's confusion is harder to clarify because his claims are fuzzier. The theory that "Reissner's fiber" is the English name for the anatomical structure known as the "sushumna nadi" in Sanskrit is straightforward and readily testable. We simply need to do scans of meditating yogins raising their kundalini energy, and see if Reissner's fiber is involved. However, the notion of boson condensation "creating a deeper relationship between our consciousness and the ultimate frontiers of physics" (Wile, 1994, p. 141) is as vague as it is unfalsifiable. On whose identification of the frontiers of physics shall we rely, and how are we to know that they are the ultimate ones? Do we all share one consciousness, as this sentence implies? Or was Wile using the "imperial we," referring only to his own consciousness? Will this one (collective or imperial) consciousness have one relationship with the plural frontiers of physics, as this sentence implies?

Neither consciousness nor the frontiers of physics are physical things. No one would imagine that either of them is located in, limited to, or researchable by boson condensation, nor by any other biophysical technique, for that matter. We must be careful not to confuse theories that apply to physical objects and processes with those that relate to concepts or categories.

\section{Kundalini}

I had always thought and spoken very highly of Gopi Krishna and kundalini research. However, the subtext of Gene Kieffer's (1994) article presented a classic case in the history of new religions: (1) the world's in deep trouble and there's no time to lose (compare the sayings of Jesus or Confucius); (2) we've got the true solution, and it 
will fix everything (again, Jesus or Confucius); (3) why doesn't anyone understand me? (4) it must be a conspiracy! "Sound the battle cry ... $[\mathrm{K}]$ undalini secrets ... give us the fighting edge in any debate with those manning the reactionary ramparts ..." (Kieffer, 1994, p. 176).

I believe there is much to be said for and about kundalini meditation. It's just that our Journal is not the place to say so much, unless each idea is clearly connected to NDEs. I am happy to have an issue of the Journal contemplate the relation of NDEs to kundalini, and I have defended its doing so to critics. My disappointment is that some of the articles are less descriptive of research results, theories, or methodology appropriate to an academic journal than polemical cants of people with particular religious axes to grind.

\section{Moses in the Wilderness}

The analogies between Moses' experience on Mt. Horeb and NDEs (Steinmetz, 1993) are again indicative of the problem of definition alluded to above. As countless earlier studies of shamans and primal religions have shown, there is an extensive range of visionary, disembodied, and otherworldly experience, in which both Moses and NDEs can find a home. Indeed, because of this very range of experience, it is hard to say that all NDEs are indeed the same experience: some may have more of the visionary; some, more of the psychic; and some, more of the ecstatic. English lacks even the vocabulary (more available in Sanskritic languages) to label and distinguish between many levels of consciousness and mental experiences. Rather than reducing Moses' experience to an NDE, or elevating all NDEs to Horeb heights, we should acknowledge Steinmetz' correctness in calling Moses' an NDE-like experience.

This, of course, raises the question of where we are to draw the line between NDEs and NDE-like experiences for the purposes of our Journal. The page between the table of contents and editor's foreword of each issue states that "The Journal publishes articles on near-death experiences and on the empirical effects and theoretical implications of such events, and on such related phenomena as outof-body experiences, deathbed visions, the experiences of dying persons, comparable experiences occurring under other circumstances...." (italics added). The criterion of comparability here becomes problematic, but the Journal could easily open itself to anthropological articles on NDE-like experiences in primal cultures; to psychiatrists' 
reflections on the family resemblances of NDEs and patients' cases; to physicists' reflections on how holograms and wormholes in physical space remind them of NDEs in mental space. In fact, isn't that exactly what's happened? I am not proposing censorship of articles reviewed for publication, but that the editorial board, of which I am still a member, ask that all articles be focused, logical, documented, nonpartisan, and paying primary attention to NDEs.

\section{Hypothetical Falsifiability and Meaninglessness}

One of Karl Popper's several great contributions to philosophy was the now widely-accepted definition of meaning in terms of propositional falsifiability. In short, it states that if no data could conceivably be adduced, or no method imagined, that might falsify a proposition or theory, then the proposition or theory is not false, but cognitively empty and meaningless (Popper and Eccles, 1977). This principle has wide application from philosophy through the hard sciences; it orients us immediately to ask: on what basis might this theory conceivably be disconfirmed? It is by searching for such disconfirmations that science receives its greatest impetus forward. Conversely, if no possible evidence would dissuade the theory-holder from the theory (such as Aristotle's volitional theory of gravity, or, I maintain, certain of the theories propounded in the articles mentioned above), then such positions are neither true nor false, but simply cognitively meaningless. This rule of thumb, already a guideline for philosophers and scientists in a wide range of fields, ought to be understood and applied to theory-building in near-death and out-of-body research.

\section{Implications}

The field of near-death research is not the place for debates about monism and dualism, which has occupied better philosophers than us for millenia, and whose resolution, even if possible, would have no immediate relevance to the survival question. It is also not the place for psychological autobiographies, polemics advocating particular religions, or articles that effectively discourage further discussion of NDEs and OBEs. Let us set aside our philosophical differences and work (1) to assemble as much information as possible about NDEs and OBEs; (2) not only to make but to test hypotheses about 
these experiences using statistically significant numbers and methodologies; and (3) to make discussion of NDEs and OBEs increasingly acceptable to the entire academic community through the high level of our work.

\section{References}

Arnette, J. K. (1992). On the mind/body problem: The theory of essence. Journal of Near-Death Studies, 11, 5-18.

Becker, C. (1993). Paranormal experience and survival of death. Albany, NY: State University of New York Press.

Blackmore, S. J. (1993). Near-death experiences in India: They have tunnels too. Journal of Near-Death Studies, 11, 205-216.

Blackmore, S. J., and Troscianko, T. (1989). The physiology of the tunnel. Journal of Near-Death Studies, 8, 15-28.

Boyer, L. B., Klopfer, B., Brawer, F. B., and Kawai, H. (1964). Comparisons of the shamans and pseudoshamans of the Apaches of the Mescalero Indian Reservation: A Rorschach study. Journal of Projective Techniques and Personality Assessment, 28, 173-180.

Enami, M. (1954). Preoptical-subcomissural neurosecretory system in the eel. Endocrinologia Japonica, 1, 133-145.

Kellehear, A. (1993). Death and renewal in The Velveteen Rabbit: A sociological reading. Journal of Near-Death Studies, 12, 35-51.

Kieffer, G. (1994). Kundalini and the near-death experience. Journal of Near-Death Studies, 12, 159-176.

Noll, R. (1985). Mental imagery cultivation as a cultural phenomenon: The role of visions in shamanism. Current Anthropology, 26, 443-452.

Popper, K. R., and Eccles, J. C. (1977). The self and its brain. New York, NY: Springer.

Ring, K. (1980). Life at death: A scientific investigation of the near-death experience. New York, NY: Coward, McCann and Geoghegan.

Ring, K. (1984). Heading toward omega: In search of the meaning of the near-death experience. New York, NY: Morrow.

Ring, K. (1992). The omega project: Near-death experiences, UFO encounters, and mind at large. New York, NY: Morrow.

Serdahely, W. J. (1992). Similarities between near-death experiences and multiple personality disorder. Journal of Near-Death Studies, 11, 19-38.

Serdahely, W. J. (1993). Near-death experiences and dissociation: Two cases. Journal of Near-Death Studies, 12, 85-94.

Steinmetz, D. (1993). Moses' "revelation" on Mount Horeb as a near-death experience. Journal of Near-Death Studies, 11, 199-203.

Wile, L. C. (1994). Near-death experiences: A speculative neural model. Journal of Near-Death Studies, 12, 133-142.

Wren-Lewis, J. (1992). Avoiding the Columbus confusion: An Ockhamish view of neardeath research. Journal of Near-Death Studies, 11, 75-81. 